there was not in one of the cases the opportunity of trying the treatment in the most hopeful stage. In addition to this, I must remark, that for a long time, until I was satisfied of the good effects of the emulsion, I did not feel justified in giving it unless for some reason the patient refused to take cod-liver oil; so that this added another unfavourable feature to the cases selected for experiment. And, again, it is important to bear in mind that the emulsion, as we first prepared it, was necessarily in a much less satisfactory condition than the emulsions used in later experiments. From time to time, Mr. Heathorn introduced great improvements in the mode of manufacture, and these have been still further carried out by Mr. Schweitzer; so that the emulsions, as now sold by Messrs. Savory and Moore, are far more satisfactory in every respect than those which we employed for the hospital cases included in my reports.

Those accustomed to hospital practice will know well that the chances of treating tuberculosis in its simple and early stage, before the occurrence of tuberculisation, are very rare. Patients do not apply at hospitals for relief until they have some marked symptoms of disease, such as hæmoptysis or purulent expectoration. When by chance they are seen in an earlier stage, they discontinue treatment directly the first feeling of debility is allayed. It is in private practice that the opportunity arises for detecting commencing tuberculosis; and it is especially within the province of the family doctor, frequenting the houses of his patients for other maladies, to keep a watch, especially in consumptive families, for the earliest dawn of impending tuberculosis.

In conclusion, I wish particularly to impress that, if the views here brought forward are correct, the importance of pancreatic emulsions of solid fat over cod-liver oil, in the treatment of tuberculosis, must be as great as that of supplying a plant with good soil instead of putting it into water. In the one case, a provision is made for the maintenance of normal life; in the other, death is only postponed by a temporary expedient.

Harley Strcet, January $18 C 6$.

NOTES ON SOME OF THE CAUSES WHICH OCCASIONALLY 'TEND TO ENDANGER FOETAL LIFE DURING LABOUR:

WITH REMARKS ON SOME OF THE MEDICO-LEGAL BEARINGS.

By G. K. H. Paterson, L.R.C.P.Ed., L.R.C.S., Balbeggie, Perthshire.

[Read before the Perthshire Medical Association.]

Is general domiciliary nidwifery, it will not, I trust, be disputed for a moment that occasionally is witnessed the occurrence of, or, if not, the tendency to, " hazardous states" in certain kinds of labour, calculated more or less to endanger fœtal life. Doubtless, not a few labour-cases-oftener in some years than in others-at the first visit by the summoned medical practitioner, are found in their early stage, and, to the best of his judgment, favourable; in which, however, it is far from being uncommon to find, when an eramination per vaginam is later made, that they have become either difficult or complicated labours.

Accordingly, it will be allowed, from the occasional uncertainty of the result in these cases, that it is an important and valuable attainment in midwifery practice to be able to make a right discrimination between the nature of the presentation in each individual case from others known to happen, as well as timely to determine as to the mode of management most fitting, and when to proceed in aiding the parturient woman; whether it be by administering needful nourishment or other means internally, or $\overrightarrow{\vec{F}}$ by the mouth, or by having timely recourse to arti- $\frac{\text { P }}{4}$ ficial interference with the same end in view, to promote and procure as speedy delivery as possible, with safety to the mother and to the child.

Having thus premised, I now proceed to state my $\frac{\sigma}{\overparen{D}}$ views in detail, though briefly, as follows.

How far the tendency oftentimes, in difficult and complicated labours, to endanger fotal life, may be obviated, must undoubtedly depend much on the na- $\overrightarrow{0}$ ture of the presentations and severity or tediousness of the cases, and on their management. Putting $\vec{\omega}$ off proper medical assistance too long, or not sending for it in time, often endangers the lite of the fœtus.

The management of cases of lingering or difficult 3 . labour (although often there is no occasion for over-anxiety from fear of danger), when timely and pro- iv perly attended to, often ends well for both lives.

Cases of difficult labour have hitherto come often ? under my observation with cephalic presentation $\vec{A}$ chiefly, not a few of which, as might be expected, $\vec{A}$ were accompanied in primiparæ with rigidity of $\frac{}{3}$ parts; and the labour in some of these went on with considerable difficulty, owing to the os uteri and $O$ other parts taking a much longer time than ordinary 7 to dilate and relax before the foetal head was suffi- $\frac{\mathbb{O}}{0}$ ciently advanced for delivery, notwithstanding the previous use of internal means. Where, on the other hand, there were present (rendering the labour, for the time they lasted, more than usually slow and $\vec{\infty}$ difficult) signs in the maternal passages of coiling of labour, ergot of rye had been early made use of, and $\square$ before the head was well advanced, I have seldom seen the expected benefits accruing from the ergot favourable to the fœetus.

In my own practice, coiling of the cord round the neck or body of the foetus has been found only in the $\frac{\mathrm{O}}{\mathrm{Q}}$ child-births of multiparous women; and I have ob- 음 served such an occurrence to endanger fotal life in no $\overrightarrow{\overrightarrow{0}}$ small number of those. Misplacement or unnatural shortness alone of the cord, when the fotal head is in the pelvis, and there is found plenty of room for the head to pass through, may be suspected to exist, if, during the time of the continuance of pretty strong and regular pains, the head slowly advance in a given time, and it be ascertained that the latter retreats after each pain, while previously the os uteri has become well dilated.

Nevertheless, and at the same time relying a good deal on the above signs of the existence of coiling or $ᄋ$ twisting of the fotal cord, I have used ergot and the forceps less than formerly; preferring non-inter- 윽 ference to pushing cases of this kind, when there was no urgent symptom calling for active aid; and $I N$ have never had to regret doing so. But, should the $D$ cord be supposed to be around the neck of the fœtus, and notwithstanding it may be the chief cause of retarding the progress of the labour, when not con- N tinuing beyond a reasonable time, it is even safer to N omit than to have recourse to ergot; and there is less $\omega$ danger to fotal life, except the labour be near its termination; then it may be found very serviceable at times.

Still there are cases, doubtless, in which it is often necessary to give ergot, and with excellent re- $\mathbb{D}$ sults; as when the labour is hindered by inefficient? uterine action, the os uteri being well dilated at the $T$ same time, the membranes broken or artificially rup- $\overline{0}$ tured, and the pelvic room being ample, with no dis- $\mathbb{D}$ cordance between the bony parts and the foetal head, $\frac{\rho}{T}$ the latter having advanced to the pelvic outlet or $\subseteq$ hollow of the sacrum.

On the contrary, it is rare to find the child alive when ergot is given too early, or some time before $?$ 
delivery can be safely effected, or after the liquor amnii has flowed away spontaneously of itself and prematurely, or has been too soon artificially let off, and when the os uteri is not much dilated, and is not very soon dilatable, the head not advancing in proportion to the length of time the parturient woman has been in labour; and more especially if, after the administration of ergot, the labour be not terminated within a reasonable time afterwards, or if it be allowed to linger on too long, instead of artificial assistance being employed as soon as the case is favourable for or demands this.

When the aforementioned signs are found in the maternal passages of the hindrance of the fotal head during labour from coiling or twisting of the umbilical cord round the neck or other parts of the body of the fœetus, the labour is generally longer in its duration, as well as being accompanied oftentimes with sharp pains of unusual severity; and to my mind it has seemed to be both safer and better practice to omit ergot and the forceps in such cases until towards the close of the labour, if needed, on account of the occasional subsiding of the maternal pains. At this stage, its administration in the usual form and doses will tend less to endanger fotal life, and also shorten or expedite the lahour. In reference to the latter cases alluded to, my usual practice for years past has been and still is, to let Nature for a reasonable time do her own work, and to render extra aid only if necessary for the safety of both mother and child.

I shall merely at present add a few of the causes in the maternal passages, etc., that have conduced more or less to put into hazard, from "dangerous pressure", the life of the fotus in cases to which I was called to render aid.

The fœtal head may be found resting too long on an unyielding perinæum, or combined with rigidity of parts, especially early and late in life (first pregnancies at full term).

In presentation of the head, it only may be expelled, and delay in expulsion may urise from want of sufficient uterine pains to expel the shoulders when large.

In footling and breech cases, the head may be large, and not cautiously and speedily delivered.

Unusual projection of the promontory of the sacrum may prevent the head from descending, in consequence of too little space.

The foetal head may be too long delayed in the pelvis or outlet of it during labour, from inefficient uterine action or unusual rigidity of parts.

There may be prolapse of the cord, internal and external; or it may be coiled round the neck and other parts of the body of the fœtus, producing liability to pressure of a dangerous kind.

The fortal head (male) may be firmly ossified, and rather larger than ordinary, and may be much and long pressed into the pelvis during labour, before its expulsion or delivery.

The child may be born in its membranes.

Maternal mental impressions may have an influence on the labour by retarding it.

The fotal head may be delayed too long in the outlet of the pelvis, from exhaustion occurring during protracted labour.

A large foetal umbilical hernia may produce delay. Accidental hæmorrhage may occur.

With such causes and conditions, certainly we have a wide field for highly important and valuable investigations, as well as for interesting questions, obstetrical and physiological, and more especially in a medicolegal point of view, and which may not be deemed unworthy of being recorded.

$$
\text { [To be continued. }]
$$

\section{CASE OF HERMAPHRODISM.}

By John H. Webster, M.D., Northampton.

THe following case of hermaphrodism, which has recently come under my observation, is worthy of being placed on record.

C. D., aged 19, in service as kitchen-maid, 5 feet 6 inches in height, weighing 8 stone 11 lbs., fairly nourished, up to the age of 16 possessed of remarkable muscular power and activity. At that period, carrying heary weights brought on uneasiness in the right iliac region, amounting at times to pain. A swelling shortly appeared, which slowly increased in size, occasioning more and more suffering upon exertion, and ultimately incapacitating her for work and holding her situation. In consequence of this and disturbance of her general health, her mother sought my opinion; stating that there was "something wrong" with her, and " matters were not with her as usual in females". The mother also mentioned that she had given birth to another child not properly formed; that, though baptised as a female, the late Mr. Charles Dodd, of this town, gave his opinion that it should have been christened as a male. This infant died at the age of three months ; it was apparently a case of extroversion of the bladder.

C. D., has a hoarse gruff voice, which changed to its present tone at the age of 13 years. There is downy hair on the upper lip. The thyroid body is more prominent and developed than is usual in the female. The sternum is somewhat projecting, and the chest rounded. The breast and nipples are quite flat and small, as in the male. There is more than usual axillary hair. The surface of the body and extremities is of feminine whiteness, and free from hair.

In the right inguinal region is a hernia as large as an orange, which, in the recumbent position, is easily reducible; but, when down, occasions a desire of frequent micturition and inability to pass motions. Within this swelling, the fingers readily detect a small flattened ellipsoidal body, well defined in its margins, somewhat larger than an almond. Pressure upon this body, or the act of coughing driving it upon the fingers, produces a sharp short pain in the left mamma. The left inguinal ring is also patulous; but there is no present hernia. A similar body is felt striking the fingers upon coughing forcibly, somewhat tender on pressure; but no complaint is made of pain radiating to either mamma. Whether these bodies are ovaria or testes, it is not an easy question to decide.

The mons veneris is flat, sparsely covered with hair; the labia externa are softer, longer, and thinner than usual; the labia interna are merely rudimentary.

In the interval between the labial commissures, and consequently in normal position, appears the clitoris ; when unexcited, sessile in aspect from a front view; when drawn forward, or in an excited condition, it is of two and a half to three inches in length, with a circumference of nearly two inches. At the latter times, it is more sensitive, firmer to the touch, more rigid in flexing, dependent between the labia, with no automatic power of, and resisting, erection. At such times, the temperature is increased, though there is no rubescence; and to the question whether frication produced sensual gratification, a feeble negative was returned; but it was thought that it was followed by an escape of fluid or some increase of moisture in the subjacent parts. This clitoris has a well defined circular prepuce, frænum, and corona glandis. Upon the lower half of the extremity of the 